\title{
Patterns of Cell and Fiber Vulnerability in the Mesostriatal System of the Mutant Mouse Weaver. I. Gradients and Compartments
}

\author{
Ann M. Graybiel, ${ }^{1}$ Keiko Ohta, ${ }^{2}$ and Suzanne Roffler-Tarlov ${ }^{3}$ \\ 'Department of Brain and Cognitive Sciences, Massachusetts Institute of Technology, Cambridge, Massachusetts 02139 , \\ 'Department of Neurology, Jichi Medical School, Minawikawachimachi, Kawachigun, Tochigi, Japan 329-04, and ${ }^{3 P r o g r a m}$ \\ in Neurosciences, Tufts University School of Medicine, Boston, Massachusetts 02111
}

In mice carrying the autosomal recessive gene weaver, there is a massive postnatal loss of dopamine in the caudoputamen, the target of the nigrostriatal system, with relative (though not complete) preservation of dopamine in the ventral striatum, a target of the mesolimbic system. There is concomitant death of catecholaminergic neurons in the substantia nigra, with much less cell death in the limbic midbrain area. In the study reported here, we have reexamined the mesostriatal system of weaver mice by means of tyrosine hydroxylase (TH) immunohistochemistry in order to determine the local architecture of the defect within the striatum and substantia nigra. For the dorsal striatum, the most striking finding was the appearance in the weaver caudoputamen of small pockets of especially weak immunostaining within a larger dorsal zone of generally reduced TH-positive neuropil. These pockets were identified as striosomes by calbindin $_{28 \mathrm{k}}$ and met-enkephalin immunohistochemistry carried out on adjacent sections. In dorsal, central, and caudal sectors of the caudoputamen, there was also more generalized depletion of TH-immunoreactive neuropil. In the midbrains of the mutants, the patterns of loss of TH-positive neurons appeared to correspond to these distributions of reduced immunostaining in the striatum. In the substantia nigra pars compacta, ventrally situated TH-positive neurons were especially affected, suggesting preferential depletion of TH-positive neurons projecting to striosomes. In addition, there was a central sector of nearly complete loss of THpositive neurons in the substantia nigra pars compacta and a marked depletion of TH-positive neurons in cell group $\mathbf{A 8}$ that, together, may have accounted for the diminution of TH-positive innervation of the striatal matrix. We conclude that the effects of the weaver gene discriminate among mesostriatal subsystems not only according to the regional affiliations of these subsystems within the dorsal and ventral striatum, but also according to the preferential association of the subsystems for the striosomal and matrical compartments of the caudoputamen. The depletion of TH-positive

\footnotetext{
Received Apr. 26. 1989; revised Aug. 10, 1989; accepted Aug. 22, 1989.

It is a pleasure to thank Drs. T. Joh, R. P. Elde, and C. Gerfen for their gifts of antisera and Ms. Diane Major and Mr. Glenn Holm for their technical support. Mr. H. F. Hall is responsible for the photography. This work was funded by NIH NS20181, the Seaver Institute, and the Whitaker Ilealth Sciences Fund. S. R.-T. is a recipient of a Research Scientist Development Award (MH00655).

Correspondence should be addressed to Dr. Ann M. Graybiel at the above address.

Copyright (C) 1990 Society for Neuroscience $0270-6474 / 90 / 030720-14 \$ 02.00 / 0$
}

innervation was not confined to the dorsal striatum proper. The defect extended into the adjoining nucleus accumbens, where it appeared to affect the lateral "core" division, and included also a lateral part of the olfactory tubercle. Thus, as in the dorsal striatum, the defect in the TH-positive innervation of the ventral striatum closely follows the local architecture of this striatal region. Neuronal loss in the ventral tegmental area was not evident on qualitative analysis, but at the border between lateral cell group A10 and medial cell group A9 there was obvious loss of immunostained neurons. It seems probable that depletion of TH-positive neurons in this transition zone contributes to the mesolimbic defect.

A central question in neurobiology is how functionally organized systems are defined genetically. For the dopamine-containing systems of the brain, the weaver mutation provides a particularly interesting disorder (Schmidt et al., 1982; Roffler-Tarlov and Graybiel, 1984, 1986, 1987; Gupta et al., 1987; Triarhou et al., 1988a, b; Doucet et al., 1989). In mice homozygous for the weaver gene, there is massive cell death of neurons in the substantia nigra and a $>70 \%$ loss of dopamine in the caudoputamen. By contrast, there is marked sparing of neurons in the limbic midbrain area and of dopamine in the ventral striatum. The defect is a developmental one. The loss of dopamine-containing innervation occurs postnatally before maturity is reached (Roffler-Tarlov and Graybiel, 1987; Roffler-Tarlov et al., 1990). The death of dopamine-containing neurons in the midbrain does not appear to be secondary either to massive death of striatal neurons or to large reductions in dopamine receptor-related binding sites (Pullara et al., 1986; Kaseda et al., 1987; Ohta et al., 1989). In fact, the earliest defect so far detected is a depletion of high-affinity dopamine uptake sites in the caudoputamen (see accompanying paper, Roffler- ' arlov et al., 1990). Thus, the dopamine-containing mesostriatal terminals themselves may be a primary target of the weaver gene.

Such findings suggest that the topography and local patterning of fiber loss in the weaver's striatum might provide clues to the events underlying expression of the disorder. With this possibility in mind, we studied the distribution of surviving catecholamine-containing fibers in the weaver's striatum with the aid of tyrosine hydroxylase $(\mathrm{TH})$ immunohistochemistry with 2 goals in mind. First, we wanted to determine in detail the pattern of fiber loss in the striatum, already known to be a notable feature of the genetic defect both in the caudoputamen and in the ventral striatum (Roffler-Tarlov and Graybiel, 1984, 
1986). Second, we wanted to learn whether there are different effects of the weaver gene on the mesostriatal innervation of the striosomal and matrical compartments of the caudoputamen. These mesostriatal innervations, the "islandic" and "diffuse" systems originally recognized in studies of development of the striatum (Olson et al., 1972; Tennyson et al., 1972), are thought to arise in different cell groups in the midbrain (Gerfen et al., 1987b; Jiménez-Castellanos and Graybiel, 1987; Langer and Graybiel, 1989), to have different developmental time courses (Olson et al., 1972; Tennyson et al., 1972; Kent et al., 1982; Graybiel, 1984a, b; Murrin and Fcrricr, 1984; Lanca ct al., 1986; Newman-Gage and Graybiel, 1988), and to be associated differently with many of the neurotransmitter systems represented in the striatum (see Graybiel, 1989, for review). In parallel, we analyzed the distributions of surviving TH-positive neurons in the midbrains of weaver and control mice to determine whether particular patterns of cell-body loss in the weaver midbrains might be correlated with local or regional inhomogeneities in fiber loss in the striatum.

\section{Materials and Methods}

Tissue. Striatal and nigral tissue was obtained from 1.5- to 4-monthold homozygous normal $(+/+)$, homozygous weaver $(w v / w v)$ mice, and littermate controls that were either verified homozygous normals $(+l$ + , later experiments) or identified only as nonweaver $(+/+$ or $+/ w v$, earlier experiments). All mice were on a $\mathrm{C}_{57} \mathrm{Bl} / 6 \mathrm{JLe}-\mathrm{A}^{\mathrm{wJ}} \times \mathrm{CBA} /$ $\mathrm{CaGnLeF}$ hybrid background. Animals from stock originally supplied by the Jackson Laboratories (Bar Harbor, ME) were bred and maintained in the laboratory colony. Brains from age-matched weavers and controls were dissected from deeply anesthetized mice perfused transcardially with $4 \%$ paraformaldehyde in $0.1 \mathrm{M} \mathrm{PO}_{4}$ buffer $-0.9 \%$ saline (PBS) containing 5\% sucrose. Blocks containing the striatum and nigral complex were postfixed briefly, washed overnight in PBS containing $20 \%$ sucrose, and cut transversely at $20-30 \mu \mathrm{m}$ on a sliding microtome. Every section through the striatum and substantia nigra was saved and processed for immunohistochemistry or histochemistry, or was stained by the Nissl method with cresylecht violet. Identification of mice as being $+/ t,+/ w v$, or $w v / w v$ was by virtue of behavior and by postmortem analysis of cerebella (Roffler-Tarlov and Turey, 1982; RofflerTarlov and Graybiel, 1986).

Immunohistochemistry. The peroxidase-antiperoxidase (PAP) method of Sternberger (1979) was followed with or without double-bridge steps according to protocols described in detail elsewhere (Roffler-Tarlov and Graybiel, 1987). Sections from weaver and littermate control brains were processed strictly in parallel and where possible in the same partitioned staining vessels. The final diaminobenzidine (DAB) step was always carried out in weaver and control sections in the same dishes. All antisera were polyclonal and raised in rabbit. Antiserum to TH was purchased from EugeneTech or received as a gift from Dr. Tong Joh. Antiserum to calbindin ${ }_{28 \mathrm{k}}$ was donated by Dr. C. Gerfen. Antiserum to met-enkephalin (mENK) was a gift from Dr. Robert Elde. Sections were pretreated successively in solutions of Tris-buffered saline (TBS) containing $\mathrm{H}_{2} \mathrm{O}_{2}(5 \mathrm{~min}), 0.2-1 \%$ Triton $\mathrm{X}-100(5 \mathrm{~min}), 3 \%$ normal goat serum (NGS) ( $30 \mathrm{~min}$ ), and, following washing in TBS, were incubated in primary antiserum (dilutions $1: 1000$ for calbindin $_{28 \mathrm{k}}$, 1:600 for antimENK, 1:500 for Joh anti-TH, and 1:240 for EugeneTech anti-TH) for $1-5 \mathrm{~d}$ at $4^{\circ} \mathrm{C}$. Sections were then washed in TBS, incubated for $30 \mathrm{~min}$ at room temperature in 1:10 goat anti-rabbit immunoglobulin (IgG), washed, incubated for $30 \mathrm{~min}$ in rabbit PAP complex (Sternberger, 1979; 1:30). For some sections, a second cycle of bridge and PAP reactions followed before the final DAB step. Occasionally, sections were treated by the osmium tetroxide intensification procedure of Adams (1981).

Histochemistry. Acetylcholinesterase (AChE) histochemistry was carried out according to the Geneser-Jensen and Blackstad method (1971) with slight modifications. For Nissl stains, sections were processed with cresylecht violet.

Analysis. Sections were studied with dark- and bright-field optics. Charts of the distribution of TH-immunoreactive regions were made for closely spaced sections (e.g., 40-60 $\mu \mathrm{m}$ apart) through the striatum and midbrain. Comparisons of patterns in serially adjacent sections were made with vascular landmarks as fiducial points. Comparisons among sections from weaver and control brains were made with care to match levels through the brains as closely as possible.

\section{Results}

Striatal chemoarchitecture in the weaver mouse Regional and compartmental deficits in TH-positive neuropil in the weaver's caudoputamen

The patterns of TH immunostaining confirmed an extensive zone of reduced catecholaminergic innervation in the dorsolateral, dorsomedial, and dorsal parts of the wcaver's caudoputamen. Figure 1 illustrates the patterns of TH immunostaining in 4 pairs of sections from a ca. 111/2-month-old $w v / w v$ mouse and its littermate control taken at intervals between the rostral and caudal poles of the caudoputamen. The region of diminished immunostaining was smallest rostrally and, at least for the level shown in Figure $1 A$, included the dorsal and laterodorsal part of the caudoputamen. At successively more caudal levels, the district of depletion broadened and deepened to include more of the caudoputamen. At the levels shown in Figure $1, B, C$, the zone of reduced immunostaining resembled a funnel, with a thin rim of surviving innervation along the medial face of the caudoputamen and a larger zone of sparing laterally. There was a focus of very dense surviving $\mathrm{TH}$-positive innervation in the lateroventral part of the caudoputamen (Fig. $1 D$ ), where, in control mice, the innervation is also massive. At caudal levels, most of the TH-positive fibers were confined to this ventral foot of the caudoputamen except for those in a thin rim of THpositive neuropil along the medial edge of the caudoputamen. Thus, considering the caudoputamen as a whole, the defect in the TH-positive innervation seemed most extensive caudally.

Even in the most affected regions, where the loss of $\mathrm{TH}$ positive neuropil in the weaver's caudoputamen was marked (Fig. 2A), surviving fibers nearly always could be detected (cf. Triarhou et al., 1988b). The decline in innervation density from ventral to dorsal levels in the caudoputamen was not abrupt (Fig. 2A). It appeared to follow a gradient extending from the zones of densest innervation ventrocaudally toward the zones of weakest innervation dorsally (Fig. $2 A$ ). Precisely how far dorsally surviving $\mathrm{TH}$-positive neuropil could be traced at any given anteroposterior level within the caudoputamen varied from weaver to weaver. Differences in the general staining intensity among the brains undoubtedly contributed to this variability, but even in apparently strongly immunostained specimens, few TH-positive fibers reached the dorsal cap of the caudoputamen in some brains, whereas in others more fibers were apparent in this dorsal zone.

A second and striking abnormality in TH immunostaining in the weaver caudoputamen was the appearance of small $(20-$ to $100-\mu \mathrm{m}$-wide) pockets of diminished $\mathrm{TH}$-positive innervation interspersed amidst the remaining fields of TH-positive neuropil (Figs. 1, 2B, 3). These zones-some rounded, others elongated to form bands - were regularly seen in rostral sections both dorsally and ventrally (Fig. $1 A$ ), and they also appeared farther caudally (Fig. 1C). The borders of the pockets were quite crisp (Figs. 2, 3), even though the zones were not completely devoid of immunostained fibers. The definition of these zones was generally sharpest in regions where considerable $\mathrm{TH}$-positive neuropil remained, but few were found in the laterocaudal part of the caudoputamen despite the strong $\mathrm{TH}$ immunostaining in this region. No comparable pockets of sparse TH immunostaining were visible in the caudoputamen in normal controls save 

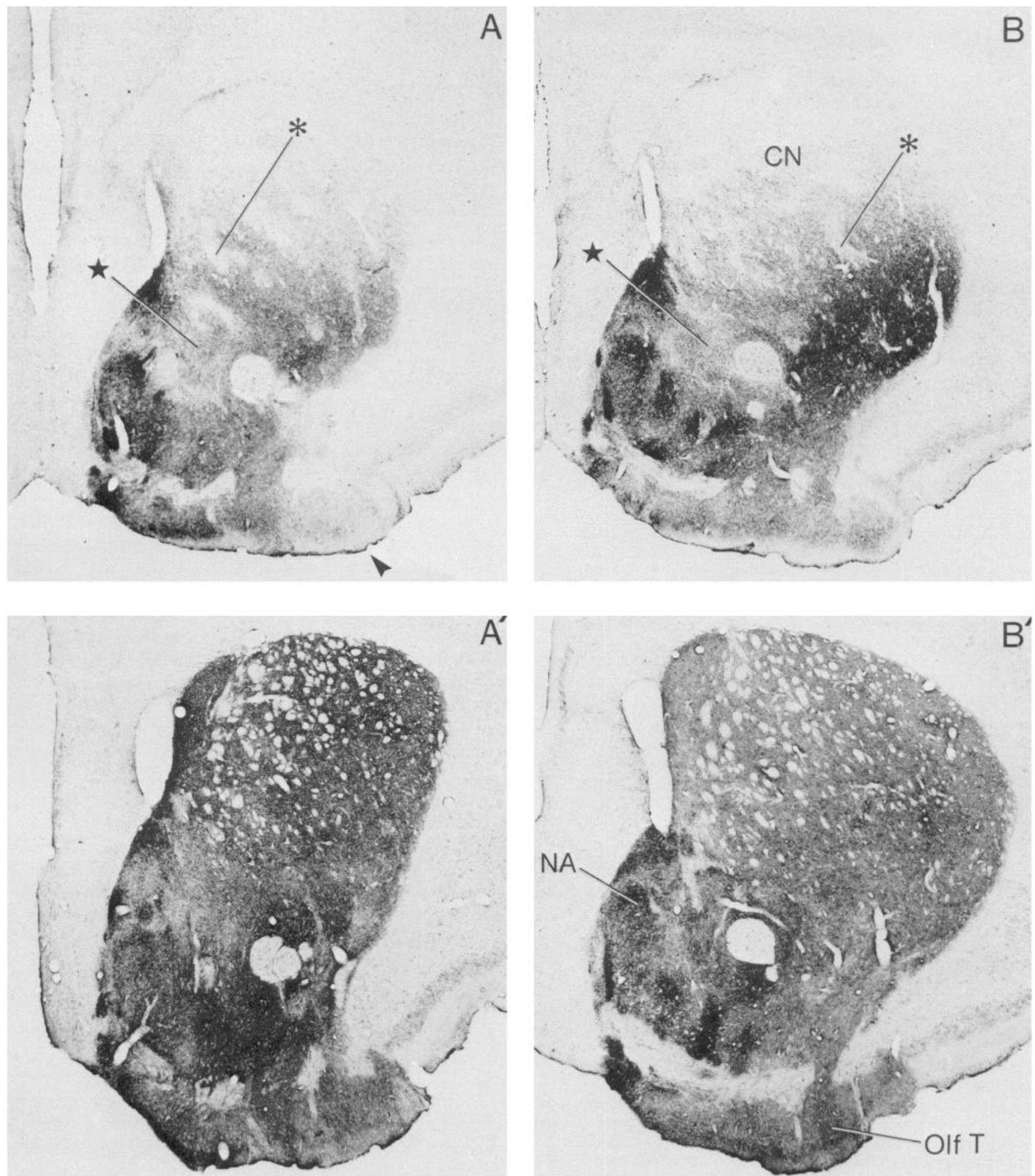

Figure 1. Patterns of TH immunostaining in 4 pairs of transverse sections taken at approximately matched levels from the brains of a homozygous weaver mouse $(A-D)$ and its littermate $(+/+$ or $+/ w v)$ control $\left(A^{\prime}-D^{\prime}\right)$. Mice MTOH-6 and 5, ca. 11 1/2 months old. Note dorsolateral and dorsal zones of depleted immunostaining in the weaver's caudoputamen, and the pockets of depleted TH-positive neuropil that appear in the more ventrally situated regions of partly spared TH-positive innervation within the caudoputamen (examples at asterisks in $A$ and $B$ ). Also note (at region indicated by stars) depletion of TH immunostaining in the lateral part of the nucleus accumbens $(A, B)$ and (at arrowheads) lateral zone of reduced $\mathrm{TH}$ immunostaining in the olfactory tubercle $(A, C)$. Intense TH-like immunoreactivity is retained in the caudoventral caudoputamen

far ventrally, at the transition between the dorsal and ventral striatum (see below).

Because these small zones of low TH-like immunoreactivity were reminiscent of histochemically defined striosomes de- scribed in many mammalian species (Graybiel and Ragsdale, 1978), we made direct serial-section comparisons between the $\mathrm{TH}$-poor zones and zones identified as striosomes with the aid of calbindin $_{28 \mathrm{k}}$ (Gerfen et al., 1985, 1987a, b) and mENK im- 

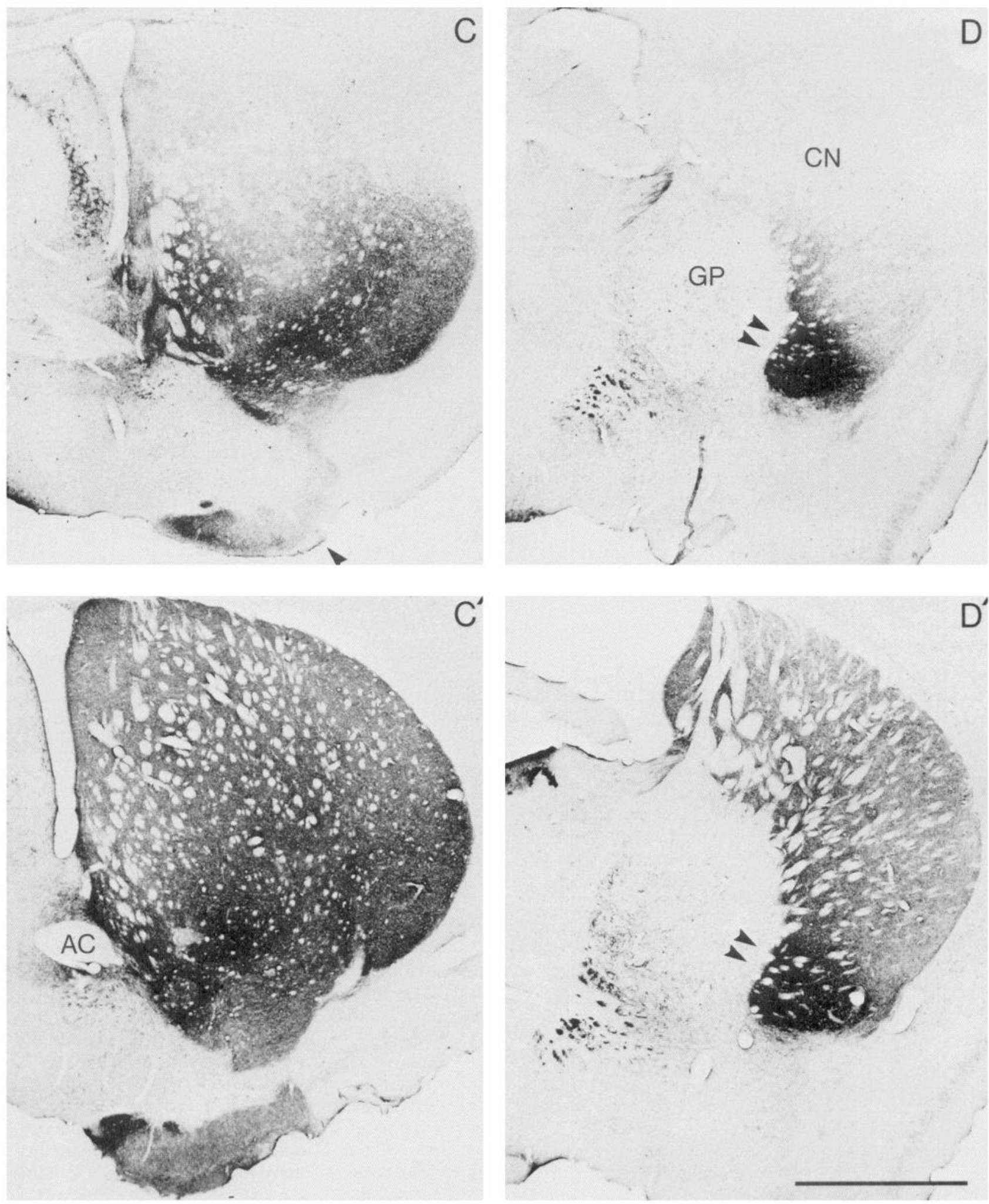

(double arrowheads in $D$, cf. $D^{\prime}$ ). Pocket of low TH-like immunoreactivity marked by asterisk in $B$ is illustrated at higher magnification in Figure $2 B$. $C N$, caudate nucleus; $N A$, nucleus accumbens; $O l f T$, olfactory tubercle; $G P$, globus pallidus; $A C$, anterior commissure. Scale bar, 1 mm.

munostaining (Graybiel and Chesselet, 1984a, b). Striosomes in the central caudoputamen are readily visible in calbindin ${ }_{28 \mathrm{k}}$ and mENK-stained sections in most species because few medium-sized neurons in striosomes express detectable calbindin ${ }_{28 \mathrm{k}^{-}}$ like or strong mENK-like immunoreactivity, whereas most medium-sized neurons in the extrastriosomal matrix do. The results of the comparisons were unambiguous in showing that the pockets of reduced $\mathrm{TH}$ immunostaining in the weaver cau- 

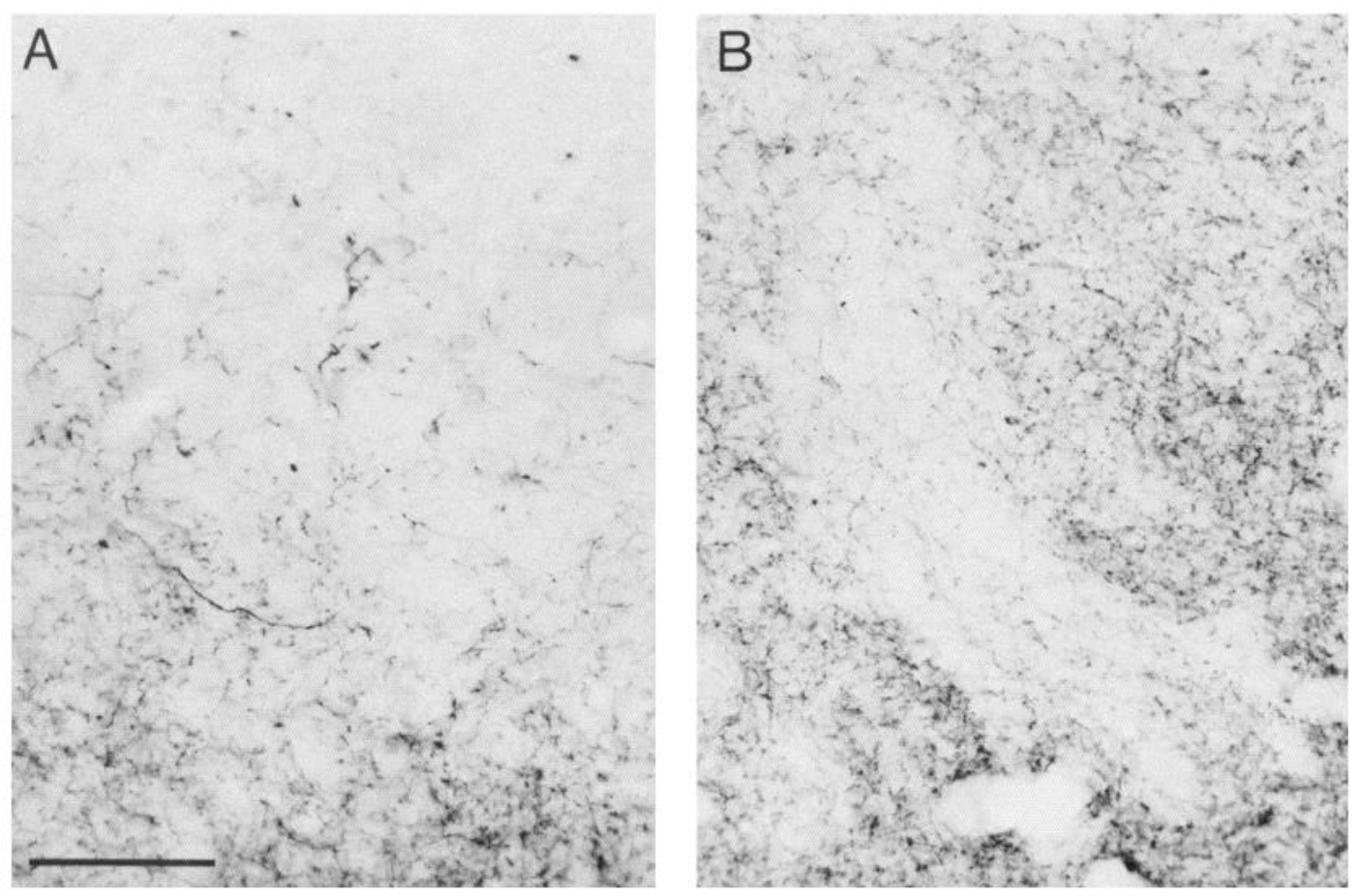

Figure 2. A, Photomicrograph illustrating the border between the dorsal zone of depleted TH-positive neuropil and the more ventral zone of relative sparing of TH immunostaining in homozygous weaver mouse MTOH-6. Note the sparsely distributed TH-positive fibers and varicosities within the dorsal zone. $B$, Pocket of depleted TH-immunoreactive innervation in mid-ventral part of the caudoputamen in this mouse; the location of the pocket is indicated by the asterisk in Figure $1 B$. Note the sparse fine-caliber fibers and varicosities remaining in the zone. Scale bar for both photographs, $100 \mu \mathrm{m}$.

doputamen corresponded to calbindin ${ }_{28 k}$-poor zones and to zones with few mENK-positive neurons. These findings are illustrated in the photomicrographs of Figure 3.

Given the close match between the calbindin ${ }_{28 \mathrm{k}}$-poor and THpoor zones found in our serial section analysis, it was natural to expect there might be a match between the regional gradients of depletion of TH immunostaining and the regional variation in calbindin ${ }_{28 \mathrm{k}}$ immunoreactivity in the caudoputamen. There were clear similarities. For example, at caudal levels, both the surviving TH-positive neuropil and the calbindin ${ }_{28 \mathrm{k}}$-immunoreactive neurons were mainly confined to the ventral foot of the caudoputamen. But at more anterior levels, the 2 staining patterns did not exactly match; the lateral zone of relatively spared TH-positive innervation overlapped the lateral zone of low calbindin ${ }_{28 \mathrm{k}}$ expression, and the calbindin ${ }_{28 \mathrm{k}}$ staining lacked the "funnel" shape characteristic of the TH immunostaining in the weavers.

\section{TH immunostaining in the nucleus accumbens and olfactory tubercle in weaver and control mice}

$\mathrm{TH}$ immunohistochemistry demonstrated intense staining in the large medial "shell" subdivision of the nucleus accumbens and in the olfactory tubercle in the controls. As shown in Figure 1 for the control mice, and as described previously for the normal rat (Fallon and Loughlin, 1987; Voorn et al., 1988a), the staining patterns in the nucleus accumbens change markedly from rostral to caudal levels and there are also differences in the mediolateral dimension. In the medial part of the nucleus, TH-positive neuropil was dense, and there were inhomogeneities in the staining intensity suggestive of regions of weaker and stronger innervation. At some levels, the medial island of Calleja was visible as a darkly immunostained zone. Laterally, however, close to the anterior commissure, the TH immunostaining was weaker, especially near the mid-length of the nucleus. At levels where the profile of the anterior commissure was visible as a transversely cut bundle, a lateral district, apparently equivaient to the "core" subdivision of the rat's nucleus accumbens (Paxinos and Watson, 1986; Voorn et al., 1988a), could be delimited in some sections. The olfactory tubercle was strongly immunostained throughout its anteroposterior extent.

In the weaver brains, the medial part of the nucleus accumbens was intensely stained for TH-like immunoreactivity and appeared normal. By contrast, the dorsolateral "core" division of the nucleus was less strongly stained than in the normal brains at middle anteroposterior levels through the striatum. The diminished staining in the nucleus accumbens appeared to be coupled to the staining pattern in the overlying caudoputamen. At rostral striatal levels, where the field of reduced TH immunostaining in the caudoputamen was least extensive, there was little defect in immunostaining visible in the accumbens region. However, at mid-levels through the caudoputamen, where its zone of diminished staining reached ventrally into the ventral part of the caudoputamen (Fig. 1B), the defect in the core of the nucleus accumbens was marked. We could not detect a border between the zones of weakened immunostaining in the core of the nucleus accumbens and in the overlying caudoputamen proper.

The TH-positive neuropil in the lateral olfactory tubercle of the weavers also was noticeably weak compared with that of the normal mice. This depletion was particularly marked at rostral and caudal levels (Fig. 1). Thus, considering the ventral striatal region across all anteroposterior levels, TH-positive neu- 

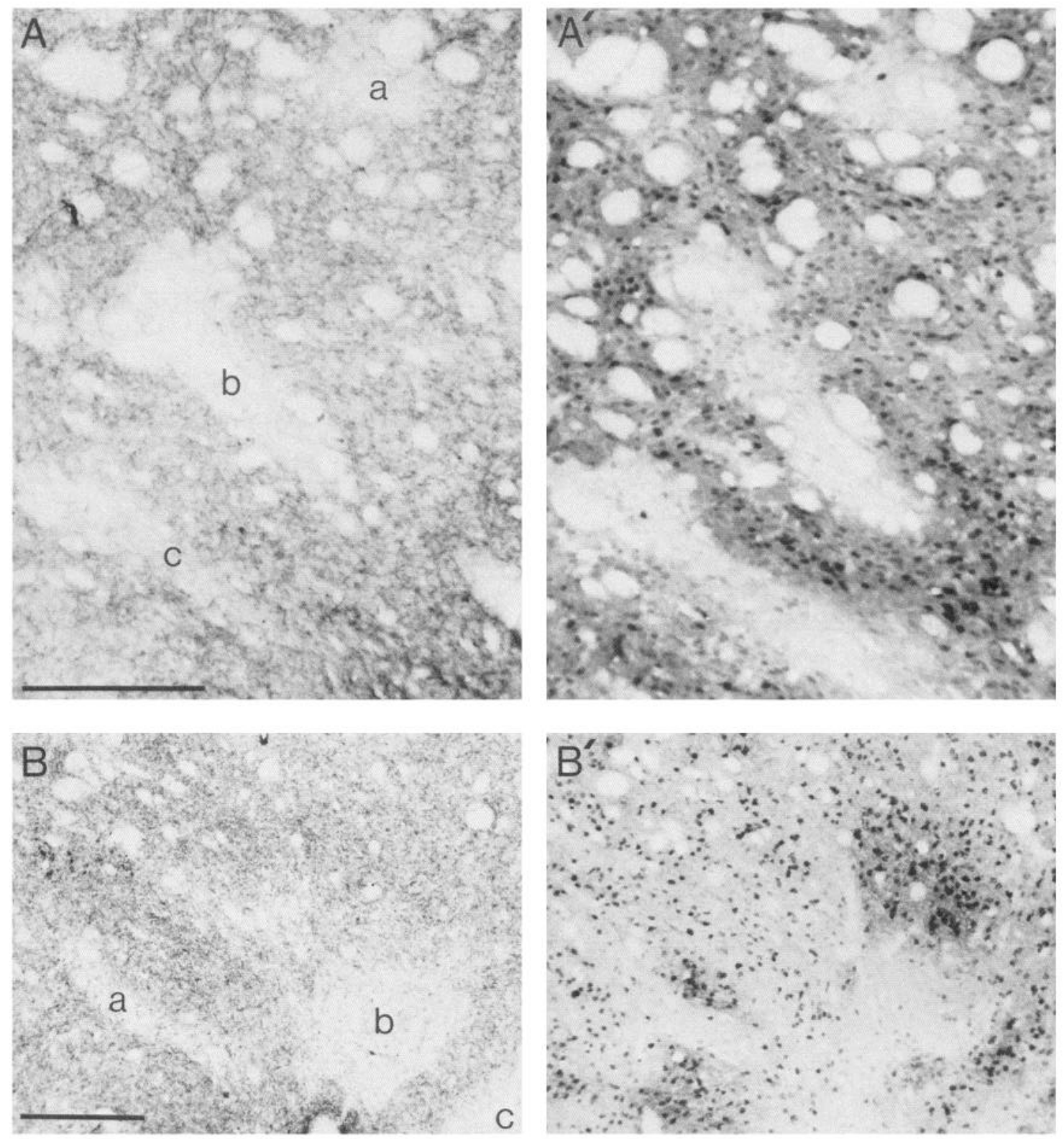

Figure 3. $A$ and $A^{\prime}$, Correspondence of pockets of low TH-like immunoreactivity $(A)$ and zones of low calbindin ${ }_{28 \mathrm{k}}$-like immunoreactivity $\left(A^{\prime}\right)$ in serial sections through the caudoputamen of an adult homozygous weaver mouse (MTOH-102). Three pockets of diminished TH-like immunoreactivity are shown $(a-c$ in $A)$, each of which matches a calbindin ${ }_{28 \mathrm{k}}$-poor striosome. $B$ and $B^{\prime}$, Comparison of immunostaining for TH $(B)$ and $\operatorname{mENK}\left(B^{\prime}\right)$ in adjacent sections from the caudoputamen of an adult homozygous weaver mouse (MTOH-28). In $B, 3$ pockets of low TH-like immunoreactivity in the caudoputamen are shown at $a-c$. Comparison with $B^{\prime}$ shows corresponding pockets of sparsely distributed mENKimmunoreactive neurons. Note in $B^{\prime}$ that patches of heightened mENK-positive neuropil lie beside the zones with sparse mENK-positive cell bodies. Scale bar, $200 \mu \mathrm{m}$.

ropil in the weaver mice seemed at least as dense as that of the normal mice medially but was clearly abnormal in lateral parts.

\section{Pattern of distribution of $\mathrm{TH}$-positive neurons in the weaver's midbrain in comparison to that in control midbrains}

There was a dramatic loss of TH-immunostained neurons in the midbrains of the weaver mice (Fig. 4), and sections stained for Nissl substance (Fig. 5) confirmed that much of this loss reflected actual depletion of cells as opposed to loss of TH-like immunoreactivity alone.

\section{Controls}

In homozygous control mice (Fig. 4, $A-C$ ), the nigral complex spans a large anteroposterior extent of the midbrain and contains groupings of TH-positive neurons recognizable as cell groups $\mathrm{A} 8, \mathrm{~A} 9$, and $\mathrm{A} 10$ originally described in the rat and extensively studied in that species (Dahlström and Fuxe, 1964; Fallon and Moore, 1978; Phillipson, 1979; Björklund and Lindvall, 1984; Fallon and Loughlin, 1985, 1987). The ventral tegmental area (cell group A10) is a dominant feature of the cell complex. Its lateral borders with the substantia nigra pars compacta (cell 

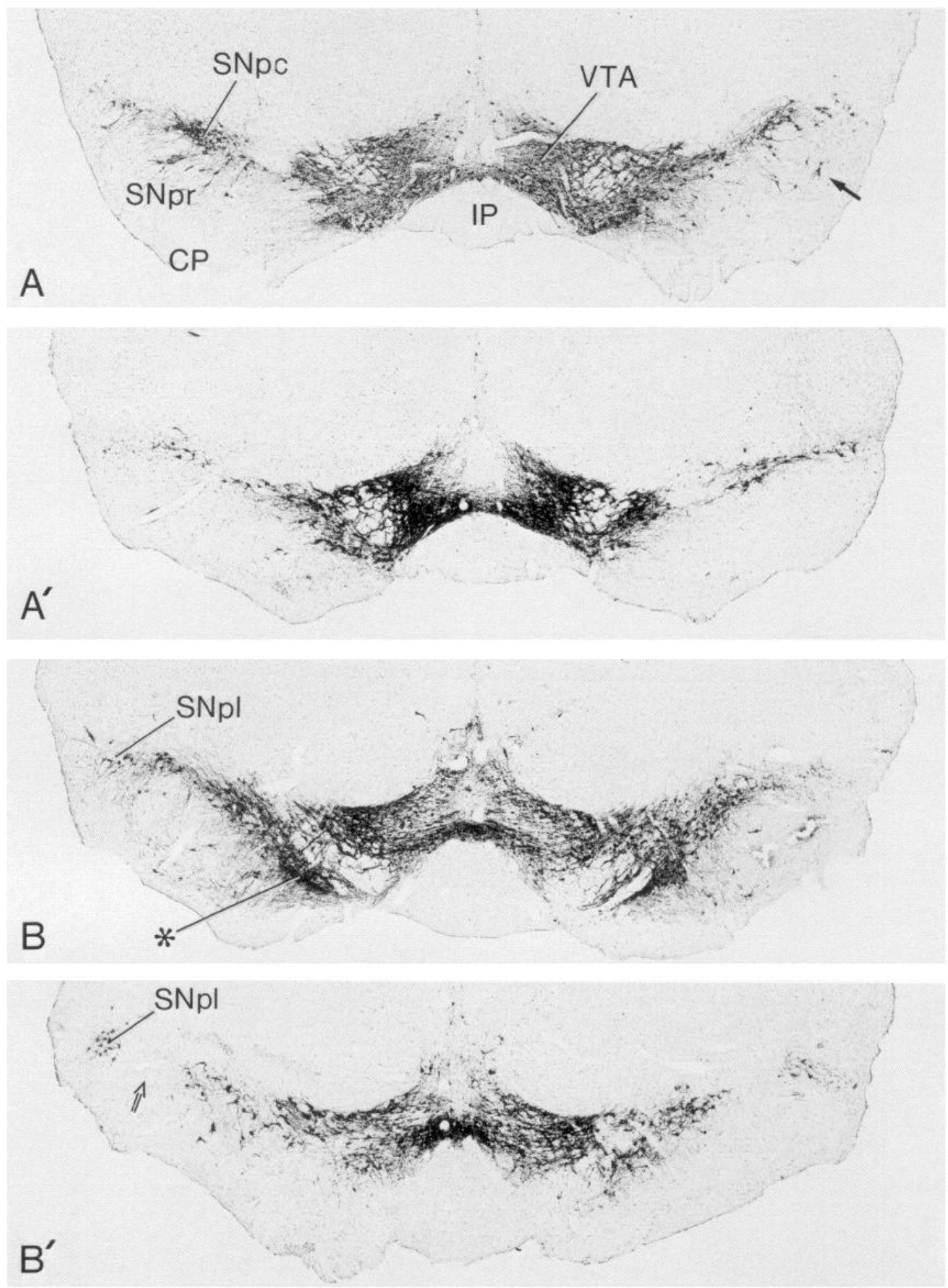

Figure 4. Pairs of TH-immunostained coronal sections at rostral $\left(A, A^{\prime}\right)$, middle $\left(B, B^{\prime}\right)$, and caudal $\left(C, C^{\prime}\right)$ levels from a 2-month-old homozygous weaver mouse (MTOH-27: $\left.A^{\prime}-C^{\prime}\right)$ and its littermate $+/+$ control (MTOH-28: $A-C$ ). The transverse levels of the sections from the 2 brains were matched as closely as possible. Arrow in $A$ points to one of the ventrally situated TH-positive neurons typical of the control's, but not the weaver's, substantia nigra. Asterisk in $B$ shows ventromedial zone densely packed with TH-positive cells and fibers and reminiscent of striosome-projecting densocellular zones of cat's substantia nigra pars compacta (Jiménez-Castellanos and Graybiel, 1987). Note it is missing in weaver $\left(B^{\prime}\right)$. Nest of TH-positive cells in the pars lateralis of the substantia nigra $(S N p l)$ survives in the weaver $\left(B^{\prime}\right.$; cf. with $\left.B\right)$ despite massive loss of TH-positive neurons in the substantia nigra pars compacta $(S N p c)$ just medial to this zone (open arrow in $B^{\prime}$ ). $C$ and $C^{\prime}$, Thinning of cell group A8, possibly including neurons ventral to brachium conjunctivum, in the weaver brain relative to that of the control (see arrow in $C$ ). $V T A$, ventral tegmental area; $I P$, interpeduncular nucleus; $S N p r$, substantia nigra pars reticulata; $C P$, cerebral peduncle; $C G S$, central gray substance; $R$, dorsal raphe nucleus; $A 8$, cell group $\mathrm{A} 8$. Scale bar, $1 \mathrm{~mm}$. 


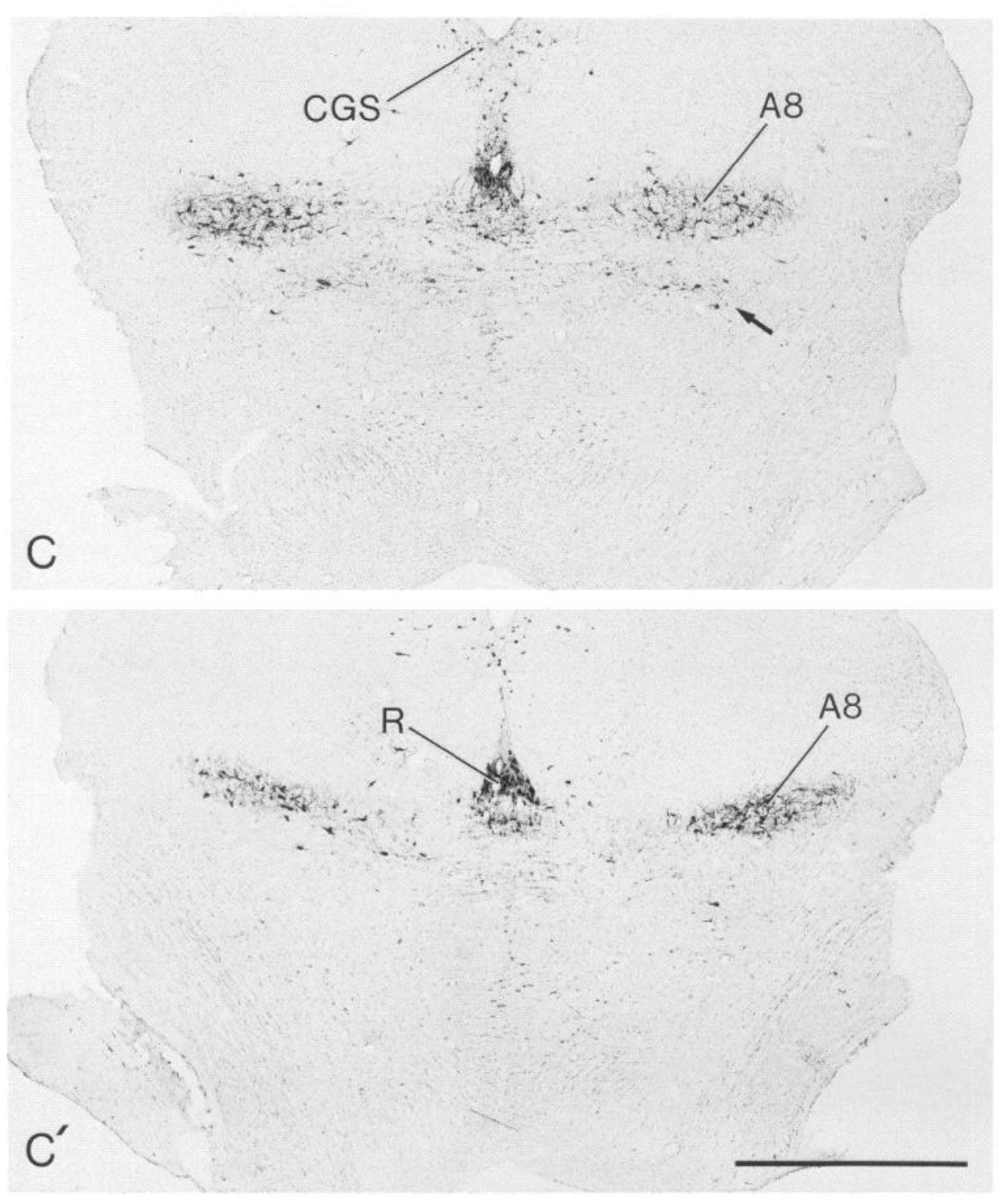

Figure 4. Continued.

group A9) and with the retrorubral nucleus (cell group A8) cannot be drawn with certainty.

Several features of the normal anatomy proved critical for the observations we made on the weavers. In the rostral half of the midbrain in the controls (Fig. 4, $A, B$ ), neurons of the substantia nigra pars compacta form a lateral wing overlying the pars reticulata and the underlying cerebral peduncle. Many of the neurons have ventrally extending dendrites that deeply penetrate the substantia nigra's pars reticulata, and TH-positive cell bodies also appear scattered singly and in small groups within the depth level of the pars reticulata (see Fig. $4 B$ ). In most sections, the TH-positive neurons form a continuous horizontal band of cells, but even in homozygous control animals the band is sometimes interrupted by short stretches in which no TH-immunostained neurons appear (not shown). The pars lateralis of the substantia nigra is recognizable as a distinct region at some but not all levels (see Fig. $4 B$ ).
A particularly striking feature of the nigral complex at progressively more caudal levels is a collection of TH-positive neurons in the ventromedial part of the substantia nigra pars compacta. This ventromedial zone (shown in Fig. $4 B$ at the asterisk) contains a dense TH-positive neuropil as well. The zone appears to be part of cell group A9 because it is ventral to the medial lemniscus, but the ventromedial zone is at the transition between cell groups A9 and A10, and only the presence of the lemniscal fiber bundles points to a separation of the zone from cell group A10. In the control mice, this zone was identified over an anteroposterior distance of about $600-700 \mu \mathrm{m}$. The region of particularly dense $\mathrm{TH}$-like immunoreactivity appears hypercellular in Nissl stains (Fig. 5C; see also Slotnick and Leonard, 1975), and it can also be recognized in AChE-stained sections as a zone of heightened enzyme staining (Fig. 5A).

Farther caudally, there is another region of transition in which TH-positive neurons appear dorsal to the medial part of the 

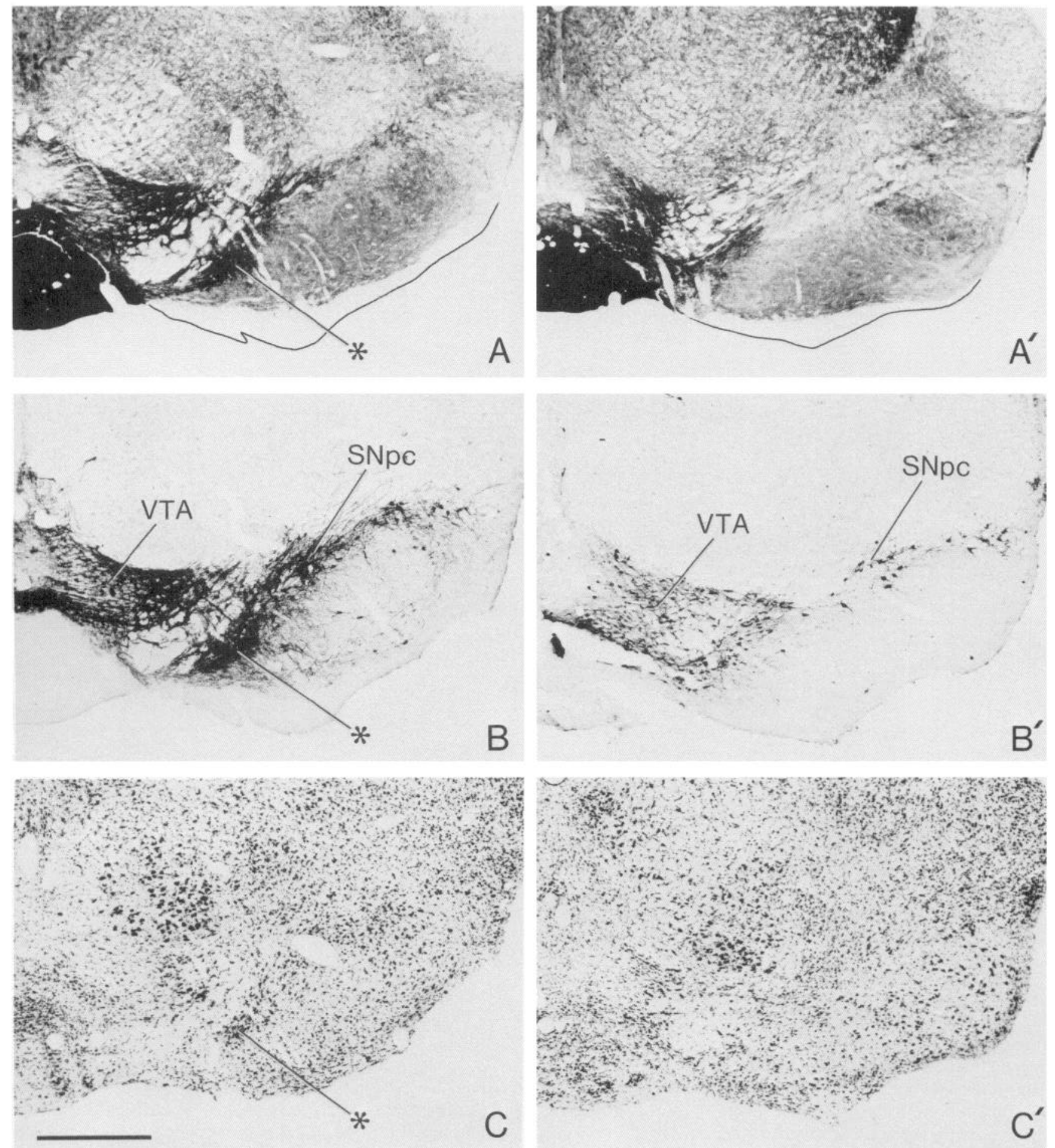

Figure 5. Near-serial sets of sections from $+/+$ control mouse MTOH-27 $(A-C)$ and homozygous weaver mouse MTOH-28 $\left(A^{\prime}-C^{\prime}\right)$ illustrating appearance of the substantia nigra pars compacta $(S N p c)$ at the level of the cell-dense ventromedial zone (asterisks in $A-C)$ in sections stained for AChE activity $\left(A, A^{\prime}\right)$, TH-like immunoreactivity $\left(B, B^{\prime}\right)$, and Nissl substance $\left(C, C^{\prime}\right)$. This cell-rich medial part of SNpc is missing in the weaver brain $\left(B^{\prime}, C^{\prime}\right)$. Some $\mathrm{AChE}$ activity survives in the region $\left(A^{\prime}\right)$, but $\mathrm{AChE}$ activity is otherwise markedly reduced in the weaver's SNpc. $V T A$, ventral tegmental area. Scale bar, $0.5 \mathrm{~mm}$. 
substantia nigra pars compacta and lateral to the main part of the A10 cell group. This dorsomedial group (not clearly shown in Fig. 4) appears to represent the anterior continuation of the A8 cell group, which is well developed at caudal levels (Fig. $4 C$ ). TH-positive neurons appear also in the raphe complex and in the central gray substance (Fig. 4C).

\section{Weaver mice}

The A8-A9-A10 complex in the weaver mouse was markedly depleted of TH-positive neurons (Fig. $4, A^{\prime}-C^{\prime}$ ). No qualitative change was evident in the median and paramedian zone corresponding to the ventral tegmental area. In the substantia nigra pars compacta, 3 abnormal patterns were evident. Altogether, these abnormalities in the immunostaining were least evident rostrally, but behind far anterior levels the sections from the weaver brains could be easily identified as such by 3 characteristics.

First, there was a severe thinning of the TH-positive cells and fibers making up the main band of the pars compacta (Fig. $4 B^{\prime}$ ). Neurons of the pars compacta having long ventrally extending dendrites were absent, or nearly so, and almost no TH-positive cell bodies appeared ventrally within the pars reticulata of the substantia nigra. Second, the ventromedial cell-dense zone typical of the normal mouse's substantia nigra pars compacta was not found in the TH-immunostained sections through the weaver's substantia nigra (See Fig. $4 B^{\prime}$ ). This striking loss of ventromedial catecholamine-containing neurons is also illustrated in Figure 5, which shows serially adjoining AChE- and Nissl-stained sections. Third, there was extreme reduction of $\mathrm{TH}$-positive neurons in the middle part of the pars compacta's transverse extent, so that in many sections there was a gap in the distribution of TH-positive neurons in this middle part of the pars compacta (Fig. $4 B^{\prime}$ ).

In nearly all but the most rostral sections through the substantia nigra, a cluster of laterally placed $\mathrm{TH}$-positive neurons remained in the weavers (see Fig. $4 B^{\prime}$ ). This cluster was evident even at levels where many, if not most, of the immediately more medially situated TH-positive neurons of the pars compacta were absent. The laterally placed $\mathrm{TH}$-positive neurons appeared to be cells of the pars lateralis of the substantia nigra, though only their lateral position could be used to identify them as belonging to this nigral subdivision.

There was a marked reduction in neurons expressing TH-like immunoreactivity in cell group A8 (Fig. $4 C^{\prime}$ ), resulting in a dorsoventral thinning of the cell group. The TH-positive neurons in the raphe complex and central gray substance of the weavers appeared to be normal in number and distribution, at least in the qualitative view afforded by the immunohistochemical sections.

\section{Discussion}

The experiments described here strongly support the view that the effects of the weaver gene are expressed in relation to functionally and developmentally distinct subdivisions of the dopamine-containing mesostriatal system.

\section{Compartmental patterns of TH-immunoreactive neuropil in the caudoputamen of weaver mutants}

For the dorsal striatum, the most remarkable finding was the patchy pattern of TH immunostaining in the weaver's caudoputamen. The evidence from calbindin ${ }_{28 k}$ and $\mathrm{mENK}$ immu- nostaining strongly suggests that the pockets of differentially weak TH immunostaining were striosomes, because they were aligned with clusters of neurons expressing low levels of calbindin $_{28 \mathrm{k}}$ and mENK-like immunoreactivity (Graybiel and Chesselet, 1984a, b; Gerfen et al., 1985, 1987a, b). The THpoor zones appeared both in districts of the caudoputamen where the TH-positive innervation of the surrounding matrix was markedly compromised and also in more ventral regions of the caudoputamen where the matrix innervation remained quite strong. In these regions, the TH-poor zones were the main feature signaling the disorder. Such TH-poor zones were never seen in the main body of the caudoputamen of the control $(+/+)$ mice.

The emergence of striosomal patterning in the TH-positive neuropil of the weavers could reflect differential depletion of the enzyme in striosome-projecting mesostriatal fibers in the mutants or accentuated loss of $\mathrm{TH}$-positive terminals in striosomes. In either case, the patchy patterns would suggest differentially greater affliction of midbrain neurons specifically innervating striosomes. It is also possible, however, that the abnormalities in neurons projecting to striosomes and in those projecting to the matrix are equivalent but that neurons innervating striosomes have more extensive local arborizations than the cells innervating the matrix, so that the effects of fiber loss in striosomes are accordingly more pronounced. By either view, the differential loss in the 2 striatal compartments might be incomplete, for some mesostriatal neurons may innervate both striosomes and matrix and the "diffuse" system may extend into striosomes. In fact, the TH-poor pockets did have a sparse remaining TH-immunoreactive innervation. There also was a spatial difference in the effects on striosomes and matrix in that the marked loss of matrical TH-positive neuropil was dorsal, but the loss of striosomal TH-positive neuropil extended farther ventrally.

We could not determine definitively which of these alternatives holds, but analysis of the weaver midbrains did suggest that the most extensive depletion of TH-positive neurons occurred in putative striosome-projecting subdivisions of the substantia nigra's pars compacta. The evidence thus points to a differential effect of the weaver mutation on fibers originating in the striosome-projecting neurons of the nigrostriatal system. This hypothesis is of considerable interest because, as discussed below, the striosome- and matrix-targeted subdivisions of the mesostriatal system have been distinguished both in terms of their developmental histories and in regard to their metabolic properties.

The dopamine island fibers that innervated striosomes appear to mature early and to maintain a developmental lead throughout a prolonged period of development over the later-maturing diffuse innervation of the striatal matrix (Olson et al., 1972; Loizou, 1972; Tennyson et al., 1972; Graybiel, 1984a, b; Murrin and Ferrier, 1984; Foster et al., 1987; Newman-Gage and Graybiel, 1988; Voorn et al., 1988a). These different schedules of development might be linked to abnormal schedules of cell death in the weaver mouse. In the weaver mutant, the islandic system is well formed at birth and is maintained during at least the first 3 weeks of development (Roffler-Tarlov and Graybiel, 1987). Only after this time is there a decline of the islandic system both dorsally (where the diffuse innervation of the matrix also is diminished) and more ventrally, where the matrical innervation is relatively better preserved (Roffler-Tarlov and 
Graybiel, 1987; Graybiel et al., 1988). It is during this prolonged postnatal period, when the islandic system is present even though the diffuse innervation is failing to develop normally, that neurons in the weaver's substantia nigra are undergoing cell death (Roffler-Tarlov et al., 1987; Triarhou et al., 1988a). A selective loss of $\mathrm{TH}$-positive fibers in striosomes has been reported to result from neonatal intrastriatal injections of the neurotoxin, 6-hydroxydopamine (Gerfen et al., 1987a). These findings have been interpreted as suggesting that when the toxin is introduced into the striatum at an early stage, it destroys the islandic system but spares the diffuse system because fibers destined to innervate the matrix have not yet reached the striatum at the time of injection or have not matured (Voorn et al., 1988b). At first glance, the defect in the weaver seems analogous because of its early onset. In weavers, however, the islands persist at least up to postnatal day 21 , when most of the loss of TH-positive cells in the midbrain has already occurred (Roffler-Tarlov et al., 1987). This schedule suggests that if there is a temporal difference in the time of affliction of the islandic (striosome-projecting) and diffuse (matrix-projecting) fibers, the islandic system is affected later than the diffuse system.

Over 15 years ago Olson and his colleagues reported another major difference between the islandic and diffuse dopamine systems of mature rats (Olson et al., 1972). On the basis of the differential responsiveness of the 2 systems to pretreatment with $\alpha$-methylparatyrosine, Olson et al. concluded that the turnover of dopamine is lower in the islandic system (innervating striosomes) than the diffuse system (innervating matrix). Their work has been confirmed and extended (Fuxe et al., 1979; Fukui et al., 1986; Ryan et al., 1988). Much more recently, it has been found in the normal human, feline, and canine striatum that striosomes characteristically appear TH-poor compared with the matrix when viewed by TH immunohistochemistry (Ferrante and Kowall, 1987; Graybiel et al., 1987; Newman-Gage and Graybiel, 1988; Turner et al., 1988). Such differences in apparent density of TH-containing neuropil have not been reported for the mature rat's caudoputamen except for its most ventral part, and they were not evident in the adult control mice in the present study. Thus, the finding of pockets of TH-poor neuropil in the weaver mutants recalls a condition visible in nonrodent species but not-at least by current techniques-in normal rodents. Interestingly, Voorn and coworkers (1988b) have noted that with antiserum to dopamine, dopamine islands can be detected at adulthood in the rat as zones of enhanced dopamine immunostaining. Their finding could be related to differential rates of turnover of the islandic and diffuse systems (Olson et al., 1972; Ryan et al., 1988). Were such differences in metabolism to hold for the 2 fiber types during the period of expression of the weaver defect, they could contribute to different vulnerability of the 2 fiber types in the weaver mutants. Given this possibility, it is especially interesting that the earliest sign of abnormality yet found for the weaver's mesostriatal system, appearing before a detectable deficit in dopamine, is in the numbers of high-affinity dopamine uptake sites in the striatum (Roffler-Tarlov and Graybiel, 1988; see accompanying paper, Roffler-Tarlov et al., 1990).

It is important to stress that the distribution of TH-immunoreactive fibers in the caudoputamen may not precisely reflect the concentration of dopamine present. Active and inactive forms of the enzyme occur (Goldstein and Greene, 1987; Grima et al., 1987; Kaneda et al., 1987) but would not be differentially detected by the antisera we used, and regulation of enzyme levels could occur without being directly reflected in altered levels of dopamine. Striosomal patterning was not evident in our original study of the weaver's mesostriatal innervation, in which we used the glyoxylic acid histofluorescence method to detect catecholamines (Roffler-Tarlov and Graybiel, 1984); and such patterning was also not reported by Doucet et al. (1989) in their study of ${ }^{3} \mathrm{H}$-dopamine uptake. These differences could be related to the sensitivities of the techniques as markers for local architecture, but they might also indicate a lack of parallelism between the levels of TH and dopamine. In fact, our own biochemical measurements do suggest that the depletion of dopamine in the dorsal caudoputamen is greater than the reduction of $\mathrm{TH}$ activity in the same zone. Conceivably, with the larger reduction in dopamine, local patterning would be abolished or imperceptible by standard anatomical methods.

A related question that we could not settle with $\mathrm{TH}$ immunohistochemistry is whether the individual residual TH-positive fibers in the weaver's caudoputamen had an abnormal morphology, as suggested by Doucet et al. (1989) on the basis of ${ }^{3} \mathrm{H}$-dopamine uptake autoradiography. Isolated TH-positive fibers were visible in and along the fringes of the dorsal zone of depletion and in the pockets of low $\mathrm{TH}$ immunoreactivity, but we did not achieve a comparable viewing of single $\mathrm{TH}$-positive fibers in the controls because the neuropil was so dense. Triarhou et al. (1988b) have reported that residual TH-positive terminals in the dorsolateral quadrant of the weaver's caudoputamen have a normal ultrastructure.

\section{Regional gradients of TH-positive fiber loss in the weaver's striatum}

The present findings confirm and extend previous observations (Roffler-Tarlov and Graybiel, 1984, 1986, 1987; Triarhou et al., 1988b; Doucet et al., 1989) in suggesting that the defect in dopamine-containing innervation in the weaver's striatum is most marked in dorsal, central, and caudal parts of the caudoputamen and that ventral, far-medial, and laterocaudal parts of the caudoputamen are least affected. These general gradients in the depletion of immunostaining were consistent from weaver to weaver, but the intensity of surviving dorsal immunostaining and the dorsal extent of the zone of weakened TH-positive innervation detected varied markedly among the animals. Interanimal variations may have reflected differences in the success of the immunohistochemical protocol in the different animals, but we do not discount epigenetic sources of variation that might influence levels of immunostaining from mouse to mouse. Interestingly, Doucet et al. (1989) also have noted individual differences in the dorsal extent of surviving ${ }^{3} \mathrm{H}$-dopamine uptake detectable by in vitro autoradiography in the weaver's caudoputamen.

As observed by Doucet et al. (1989) with anti-dopamine antibody immunohistochemistry, the lateral "core" of the nucleus accumbens in the weaver brains appeared to be differentially depleted of its dopamine-containing innervation over part of its anteroposterior extent. This loss, together with the depletion of TH-like immunoreactivity in the lateral part of the nucleus accumbens, indicates that the mesostriatal system, though relatively spared the weaver defect, nevertheless suffers a depletion. In our original description of the loss of catecholamine histofluorcscence in the wcaver's striatum, we drew special attention to the fact that the relatively spared parts of the mesostriatal system correspond to its "limbic" component, whereas the most vulnerable parts innervate the "sensorimotor" sector of the 
striatum (Heimer and Wilson, 1975). The pattern of loss in the weaver's nucleus accumbens may extend this relationship, because Groenewegen and his colleagues (1987) have shown in the rat that the core part of the nucleus accumbens is interconnected with the septal pole of the subiculum - which receives inputs from the sensory cortex - whereas the medial shell part of the nucleus accumbens receives input from the temporal subiculum - the part receiving cortical inputs related to viscerolimbic function.

\section{Dopamine-containing cell groups of the midbrain}

Analysis of TH-positive neurons in the weaver midbrains suggested a close correspondence between the patterns of fiber loss in the striatum and the patterns of cell loss in the dopaminecontaining cell groups A8-A9-A10 (see also Gupta et al., 1987; Triarhou et al., 1988a; Smith et al., 1988). The marked loss of TH-positive nigral cells in the ventral tier of the substantia nigra pars compacta is almost certainly related to the striosomal defect in the mutants. These ventral cells, by inference from findings in the rat (Gerfen et al., 1987b), should project to striosomes in the normal mouse, and they were nearly absent in the weavers. The marked depletion of neurons in cell group A8, also observed by Triarhou et al. (1988a) and Smith et al. (1988), likely contributed to the reduction of innervation of the matrix in the weaver's caudoputamen. The severe loss of dorsal as well as ventral TH-positive neurons in the middle part of the pars compacta almost certainly contributed to depletion of the TH-positive innervation of the matrix.

A striking finding in the weavers was the loss of the ventromedially situated zone of intense $\mathrm{TH}$ immunostaining in the substantia nigra. In the normal mouse, this zone had an appearance and position similar to that of the striosome-projecting "densocellular zone" of the cat's pars compacta (Jiménez-Castellanos and Graybiel, 1987). Its absence in the weaver's midbrain could be directly related to the hypoinnervation of striosomes. This nigral zone, however, is separated from the ventral tegmental area at most levels only by bundles of lemniscal fibers. Accordingly, we cannot exclude the possibility that this densest TH-immunostained zone is actually an outlying part of the A10 cell group and that, in correspondence with its lateral position, it projects to the lateral accumbens and/or lateral olfactory tubercle region in which loss of TH-positive fibers was found in the mutants.

By contrast to the severe loss of $\mathrm{TH}$-positive neurons in the midsection of the substantia nigra pars compacta, there was relative sparing of the most lateral group of $\mathrm{TH}$-positive neurons in the nigral complex, apparently corresponding to the pars lateralis of the substantia nigra. This distinct subgroup, along with cell group A8, may project to the caudoventral part of the caudoputamen, which contained a dense TH-positive innervation both in the weavers and controls (Fallon and Moore, 1978).

\section{The weaver defect in relation to other basal ganglia disorders}

Dorsal to ventral gradients in vulnerability of neural elements in the striatum have by now been recognized in disorders of the basal ganglia ranging from idiopathic Parkinson's disease (Hornykiewicz, 1979; Hornykiewicz et al., 1988; Kish et al., 1988; Graybiel et al., 1989), progressive supranuclear palsy (Agid et al., 1986), and 1-methyl-4-phenyl-1,2,3,6-tetrahydropyridine (MPTP) intoxication (Chiueh et al., 1984; Perry et al., 1985; German et al., 1988) to Huntington's disease (Vonsattel et al.,
1985; Feigenbaum et al., 1986; Ferrante et al., 1986, 1987). Interestingly, different vulnerabilities of striatal elements in striosome and matrix compartments have also been shown for some of these basal ganglia disorders (Ferrante et al., 1986; Turner et al., 1988; Seto-Oshima et al., 1989). Thus, local compartmental aspects of the weaver's mesostriatal defect, like the regional gradients in fiber loss in the mutants, share some common features with those seen in other disorders affecting the striatum.

Clearly, if the nigral neurons projecting to different parts of the striatum are topographically organized, and if the neurons projecting differentially to striosomes and to matrix are also sorted into different groups, the patterns of loss in the mesostriatal dopamine system in the weaver's striatum could be related to an initial abnormality either in the midbrain or in the forebrain. The topographies in the striatum are continuous and, though compartmental, otherwise uninterrupted. By contrast, there are several different rules relating the organization of the neurons in the midbrain to different parts of the striatum. There is a dorsoventral inversion in the topography from substantia nigra to caudoputamen but not a mediolateral inversion (Fallon and Moore, 1978), and there are specialized groupings of neurons aggregated according to their compartmental and regional targets as well (Parent et al., 1983; Gerfen et al., 1987b; JiménezCastellanos and Graybiel, 1987). The relatively simple arrangement in the striatum makes it appealing to think of the weaver defect as following striatal cues, with the patterns of mesencephalic cell loss reflecting events in the forebrain. Such retrograde reaction to events occurring in the striatum has been proposed as a mechanism underlying MPTP-induced toxicity of nigral neurons (Kitt et al., 1986; Imai et al., 1988).

\section{References}

Adams, J. C. (1981) Heavy metal intensification of DAB-based HRP reaction product. J. Histochem. Cytochem. 29: 775.

Agid, Y., F. Javoy-Agid, M. Ruberg, B. Pillon, B. Dubois, C. Duyckaerts, J.-J. Hauw, J.-C. Baron, and B. Scatton (1986) Progressive supranuclear palsy: Anatomical and biochemical considerations. Adv. Neurol. 45: 191-206.

Björklund, A., and O. Lindvall (1984) Dopamine-containing systems in the CNS. In Handbook of Chemical Neuroanatomy. Vol. 2, Classical Transmitters in the CNS, A. Björklund and T. Hökfclt, eds., pp. 55-122, Elsevier, Amsterdam.

Chiueh, C. C., S. P. Markey, R. S. Burns, J. N. Johannessen, D. M. Jacobowitz, and I. J. Kopin (1984) Selective neurotoxic effects of 1-methyl-4-phenyl-1,2,3,6-tetrahydropyridine (MPTP) in subhuman primates and man. A new animal model of Parkinson's disease. Psychopharmacol. Bull. 20: 548-553.

Dahlström, A., and K. Fuxe (1964) Evidence for the existence of monoamine containing neurons in the central nervous system. I. Demonstration of monoamines in the cell bodies of brainstem neurons. Acta Physiol. Scand. 62: 1-55.

Doucet, G., P. Brundin, S. Seth, Y. Murata, R. E. Strecker, L. C. Triarhou, B. Ghetti, and A. Björklund (1989) Degeneration and graftinduced restoration of dopamine innervation in the weaver mouse neostriatum: A quantitative autoradiographic study of $\left[{ }^{3} \mathrm{H}\right]$ dopaminc uptake. Exp. Brain Res. 77: 552-568.

Fallon, J. H., and S. E. Loughlin (1985) Substantia nigra. In The Rat Nervous System, Vol. 1 : Forebrain and Midbrain, G. Paxinos, ed., pp. 353-374, Academic, New York.

Fallon, J. H., and S. E. Loughlin (1987) Monoamine innervation of cerebral cortex and a theory of the role of monoamines in cerebral cortex and basal ganglia. In Cerebral Cortex, Vol. 6, E. G. Jones and A. Peters, eds., pp. 41-127, Plenum, New York.

Fallon, J. H., and R. Y. Moore (1978) Catecholamine innervation of the basal forebrain. IV. Topography of the dopamine projection to the hasal forebrain and neostriatum. J. Comp. Neurol. 180:545-580.

Feigenbaum, L. A., A. M. Graybiel, J.-P. Vonsattel, and E. P. Rich- 
ardson, Jr. (1986) Striosomal markers in the striatum in Huntington's disease. Soc. Neurosci. Abstr. 12: 1328

Ferrante, R. J., and N. W. Kowall (1987) Tyrosine hydroxylase-like immunoreactivity is distributed in the matrix compartment of normal human and Huntington's disease striatum. Brain Res. 416: 141-146.

Ferrante, R. J., N. W. Kowall, E. P. Richardson, Jr., E. D. Bird, and J. B. Martin (1986) Topography of enkephalin, substance $\mathbf{P}$ and acetylcholinesterase staining in Huntington's disease striatum. Neurosci. Lett. 71: 283-288.

Ferrante, R. J., M. F. Beal, N. W. Kowall, E. P. Richardson, Jr., and J. B. Martin (1987) Sparing of acetylcholinesterase-containing striatal neurons in Huntington's disease. Brain Res. 411: 162-166.

Foster, G. A., M. Schultzberg, T. Hökfelt, M. Goldstein, H. C. Hemmings, Jr., C. C. Ouimet, S. I. Walaas, and P. Greengard (1987) Development of a dopamine- and cyclic adenosine $3^{\prime}: 5^{\prime}$-monophosphate-regulated phosphoprotein (DARPP-32) in the prenatal rat central nervous system, and its relationship to the arrival of presumptive dopaminergic innervation. J. Neurosci. 7: 1994-2018.

Fukui, K., H. Kariyama, A. Kashiba, N. Kato, and H. Kimura (1986) Further confirmation of heterogeneity of the rat striatum: Different mosaic patterns of dopamine fibers after administration of methamphetamine or reserpine. Brain Res. 382: 81-86.

Fuxe, K., K. Anderson, R. Schwarcz, L. F. Agnati, M. Perez de la Mora, T. Ilökfelt, M. Goldstcin, and L. Fcrland (1979) Studies of different types of dopamine nerve terminals in the forebrain and their possible interactions with hormones and with neurons containing GABA, glutamate, and opioid peptides. In Advances in Neurology, Vol. 24, L. J. Poirier, T. L. Sourkes, and P. J. Bédard, eds., pp. 199-215, Raven, New York

Geneser-Jensen, F. A., and J. W. Blackstad (1971) Distribution of acetylcholinesterase in the hippocampal region of the guinea pig. $\mathrm{Z}$. Zellforsch Mikrosk. Anat. 114: 460-481.

Gerfen, C. R., K. G. Baimbridge, and J. J. Miller (1985) The neostriatal mosaic: Compartmental distribution of calcium-binding protein and parvalbumin in the basal ganglia of the rat and monkey. Proc. Natl. Acad. Sci. USA 82: 8780-8784.

Gerfen, C. R., K. G. Baimbridge, and J. Thibault (1987a) The neostriatal mosaic: III. Biochemical and developmental dissociation of patch-matrix mesostriatal systems. J. Neurosci. 7: 3935-3944.

Gerfen, C. R., M. Herkenham, and J. Thibault (1987b) The neostriatal mosaic: II. Patch-and matrix-directed mesostriatal dopaminergic and non-dopaminergic systems. J. Neurosci. 7: 3915-3934.

German, D. C., M. Dubach, S. Askari, S. G. Speciale, and D. M. Bowden (1988) 1-methyl-4-phenyl-1,2,3,6-tetrahydropyridine-induced parkinsonian syndrome in Macaca fascicularis: Which midbrain dopaminergic neurons are lost? Neuroscience 24: 161-174.

Goldstein, M., and L. A. Greene (1987) Activation of tyrosine hydroxylase by phosphorylation. In Psychopharmacology: The Third Generation of Progress, F. Meltzer, ed., pp. 75-80, Raven, New York.

Graybiel, A. M. (1984a) Correspondence between the dopamine islands and striosomes of the mammalian striatum. Neuroscience 13: 1157-1187.

Graybiel, A. M. (1984b) Modular patterning in the development of the striatum. In Cortical Integration, F. Reinoso-Suarez and C. AjmoneMarsan, eds., pp. 223-235, Raven, New York.

Graybiel, A. M. (1989) Dopaminergic and cholinergic systems in the striatum. In Neural Mechanisms in Disorders of Movement. A. Crossman and M. A. Sambrook, eds., pp. 3-15, Libbey, London.

Graybiel, A. M., and M.-F. Chesselet (1984a) Compartmental distribution of striatal cell bodies expressing met-enkephalin-like immunoreactivity. Proc. Natl. Acad. Sci. USA 81: 7980-7984.

Graybiel, A. M., and M.-F. Chesselet (1984b) Striatal cell bodies expressing dynorphin B-like (DYN) and met-enkephalin-like (ENK) immunoreactivities have complementary distributions in kittens and contrasting distributions in cats. Soc. Neurosci. Abstr. 10: 514.

Graybiel, A. M., and C. W. Ragsdale (1978) Histochemically distinct compartments in the striatum of human, monkey, and cat demonstrated by acetylthiocholinesterase staining. Proc. Natl. Acad. Sci. USA $75: 5723-5726$

Graybiel, A. M., E. C. Hirsch, and Y. A. Agid (1987) Differences in tyrosine hydroxylase-like immunoreactivity characterize the mesostriatal innervation of striosomes and extrastriosomal matrix at maturity. Proc. Natl. Acad. Sci. USA 84: 303-307.

Graybiel, A. M., K. Ohta, and S. Roffler-Tarlov (1988) Toward a genetic analysis of the striosomal system: Patterns of nigrostriatal loss in the mutant mouse weaver. Soc. Neurosci. Abstr. 14: 1066.

Graybiel, A. M., E. C. Hirsch, and Y. Agid (1989) The nigrostriatal system in Parkinson's disease. In Ninth International Symposium on Parkinson's Disease (in press).

Grima, B., A. Lamouroux, C. Boni, J.-F. Julien, F. Javoy-Agid, and J. Mallet (1987) A single human gene encoding multiple tyrosine hydroxylases with different predicted functional characteristics. Nature 326: 707-711.

Groenewegen, H. J., E. Vermeulen-Van der Zee, A. te Kortschot, and M. P. Witter (1987) Organization of the projections from the subiculum to the ventral striatum in the rat. A study using anterograde transport of Phaseolus vulgaris leucoagglutinin (PHA-L). Neuroscience 23: 103-120.

Gupta, M., D. L. Felten, and B. Ghetti (1987) Selective loss of monoaminergic neurons in weaver mutant mice-an immunocytochemical study. Brain Res. 402: 379-382.

Heimer, L., and R. D. Wilson (1975) The subcortical projections of the allocortex: Similarities in the neural associations of the hippocampus, the piriform cortex, and the neocortex. In Golgi Centennial Symposium Proceedings, M. Santini, ed,. pp. 177-193, Raven, New York.

Hornykiewicz, O. (1979) Brain dopamine in Parkinson's disease and other neurological disturbances. In The Neurobiology of Dopamine, A. S. Horn, J. Korf, and B. H. C. Westerink, eds., pp. 633-654, Academic, New York.

Hornykiewicz, O., C. Pifl, G. Schingnitz, and S. J. Kish (1988) The cause of Parkinson's disease: MPTP, ageing, and the striatal dopamine loss. In Neurodegenerative Disorders: The Role Played by Endotoxins and Xenobiotics, G. Nappi, ed., pp. 73-80, Raven, New York.

Imai, H., T. Nakamura, K. Endo, and H. Narabayashi (1988) Hemiparkinsonism in monkeys after unilateral caudate nucleus infusion of 1-methyl-4-phenyl-1,2,3,6-tetrahydropyridine (MPTP): Behavior and histology. Brain Res. 474: 327-332.

Jiménez-Castellanos, J., and A. M. Graybiel (1987) Subdivisions of the dopamine-containing A8-A9-A 10 complex identified by their differential mesostriatal innervation of striosomes and extrastriosomal matrix. Neuroscience 23: 223-242.

Kaneda, N., K. Kobayashi, H. Ichinose, F. Kishi, A. Nakazawa, Y. Kurosawa, K. Fujita, and T. Nagatsu (1987) Isolation of a novel cDNA for human tyrosine hydroxylase: Alternative RNA splicing produces four kinds of mRNA from a single gene. Biochem. Biophys. Res. Commun. 146: 971-975.

Kaseda, Y., B. Ghetti, W. C. Low, J. A. Richter, and J. R. Simon (1987) Dopamine D2 receptors increase in the dorsolateral striatum of weaver mutant mice. Brain. Res. 422: 178-181.

Kent, J. L., C. B. Pert, and M. Herkenham (1982) Ontogeny of opiate receptors in rat forebrain: Visualization by in vitro autoradiography. Dev. Brain Res. 2: 487-504.

Kish, S. J., K. Shannak, and O. Hornykiewicz (1988) Uneven patterns of dopamine loss in the striatum of patients with idiopathic Parkinson's disease-Pathophysiologic and clinical implications. N. Eng. J. Med. 318: 876-880.

Kitt, C. A., L. C. Cork, F. Eidelberg, T. H. Joh, and D. L. Price (1986) Injury of nigral neurons exposed to 1-methyl-4-phenyl-1,2,3,6-tetrahydropyridine: A tyrosine hydroxylase histochemical study in monkey. Neuroscience 17: 1089-1 103.

Lanca, A. J., S. Boyd, B. E. Kolb, and D. van der Kooy (1986) The development of a patchy organization in the rat striatum. Dev. Brain Res. 27: 1-10.

Langer, L. F., and Graybiel, A. M. (1989) Distinct nigrostriatal projection systems innervate striosomes and matrix in the primate striatum. Exp. Brain Res. (in press).

Loizou, L. A. (1972) The postnatal ontogeny of monoamine-containing neurones in the central nervous system of the albino rat. Brain Res. 40: 395-418.

Murrin, L. C., and J. R. Ferrier (1984) Ontogeny of the rat striatum: Correspondence of dopamine terminals, opiate receptors and acetylcholinesterase. Neurosci. Lett. 47: 155-160.

Newman-Gage, H., and A. M. Graybiel (1988) Expression of calcium/ calmodulin dependent protein kinase in relation to dopamine islands and synaptic maturation of cat striatum. J. Neurosci. 8: 3360-3375.

Ohta, K., A. M. Graybiel, and S. Roffler-Tarlov (1989) Dopamine D1 binding sites in the striatum of the mutant mouse weaver. Neuroscience $28: 69-82$. 
Olson, L., A. Seiger, and K. Fuxe (1972) Heterogeneity of striatal and limbic dopamine innervation: Highly nuorescent islands in developing and adult rats. Brain Res. 44: 283-288.

Parent, A., A. Mackey, and L. De Bellefeuille (1983) The subcortical afferents to caudate nucleus and putamen in primates: A tluorescence retrograde double labeling study. Neuroscience 4: 1137-1150.

Paxinos, G., and C. Watson (1986) The Rat Brain in Stereotaxic Coordinates, Academic, New York.

Perry, T. L., V. W. Yong, K. Jones, R. A. Wall, R. M. Clavier, J. G. Foulkes, and J. M. Wright (1985) Fffects of n-methyl-4-phenyl1,2,3,6-tetrahydropyridine and its metabolite n-methyl-4-phenylpyridinium ion on dopaminergic nigrostriatal neurons in the mouse. Neurosci. Lett. 58: 321-326.

Phillipson, O. T. (1979) The cytoarchitecture of the interfascicular nucleus and ventral tegmental area in the rat. J. Comp. Neurol. 187: 85-98.

Pullara, J. M., D. W. Sapp, J. N. Joyce, and J. F. Marshall (1986) Corresponding regional influences of the weaver mutation on striatal dopaminergic innervation and receptor distribution. Soc. Neurosci. Abstr. 12: 1225.

Roffler-Tarlov, S., and A. M. Graybiel (1984) Weaver mutation has differential effects on the dopamine-containing innervation of the limbic and non-limbic striatum. Nature 307: 62-66.

Roffler-Tarlov, S., and A. M. Graybiel (1986) Expression of the weaver gene in dopamine-containing neural systems is dose-dependent and affects both striatal and non-striatal regions. J. Neurosci. 6: 33193330.

Roffler-Tarlov, S., and A. M. Graybiel (1987) The postnatal development of the dopamine-containing innervation of dorsal and ventral striatum: Effects of the weaver gene. J. Neurosci. 7: 2364-2372.

Roffler-Tarlov, S., and A. M. Graybiel (1988) Regional effects of the weaver gene on presynaptic dopamine uptake sites in striatum. Soc. Neurosci. Abstr. 14: 1066.

Roffler-Tarlov, S., and M. Turey (1982) The content of amino acids in the developing cerebellar cortex and deep cerebellar nuclei of granule cell deficient mutant mice. Brain Res. 247: 65-73.

Roffler-Tarlov, S., A. M. Graybiel, B. Martin, and J. Kauer (1987) The mesencephalic dopamine-containing neurons in the weaver mouse. Soc. Neurosci. Abstr. 13: 1599.

Roffler-Tarlov, S., D. Pugatch, and A. M. Graybiel (1990) Patterns of genetically programmed cell and fiber vulnerability in the mesostriatal system of the mutant mouse weaver. II. High affinity uptake sites for dopamine. J. Neurosci. 10: 734-740.

Ryan, L. J., M. E. Martone, J. C. Linder, and P. M. Groves (1988) Continuous amphetamine administration induces tyrosine hydrox- ylase immunoreactive patches in the adult rat neostriatum. Brain Res. Bull. 21: 133-137.

Schmidt, M. J., B. D. Sawyer, K. W. Perry, R. W. Fuller, M. M. Foreman, and B. Ghetti (1982) Dopamine deficiency in the weaver mutant mouse. J. Neurosci. 2: 376-380.

Seto-Oshima, A., P. C. Emson, L. H. Carassco, and E. Lawson (1989) Selective damage to the striatal matrix in Huntington's disease. In Neural Mechanisms in Disorders of Movement, A. R. Crossman and M. A. Sambrook, eds., Libbey, London.

Slotnick, B. M., and C. M. Leonard (1975) A Stereotaxic Atlas of the Albino Mouse, U.S. Department of Health, Education and Welfare, Rockville, MD.

Smith, D. E., M. W. Smith, III, T. R. Cooper, and T. H. Joh (1988) Shifts in class distribution of TH-labeled cells in the substantia nigra of the neurological mutant mouse weaver. Soc. Neurosci. Abstr. 14: 1066.

Sternberger, L. A. (1979) Immunocytochemistry, Wiley, New York.

Tennyson, V. M., R. E. Barrett, G. Cohen, L. Côté, R. Heikkila, and C. Mytilneou (1972) The developing neostriatum of the rabbit: Correlation of fluorescence histochemistry, electron microscopy, endogenous dopamine levels, and $\left[{ }^{3} \mathrm{H}\right]$ dopamine uptake. Brain Res. 46 . 251-285.

Triarhou, L. C., J. Norton, and B. Ghetti (1988a) Mesencephalic dopamine cell deficit involves areas $A 8, A 9$, and $A 10$ in weaver mutant mice. Exp. Brain Res. 70: 256-265.

Triarhou, L. C., J. Norton, and B. Ghetti (1988b) Synaptic connectivity of tyrosine hydroxylase immunoreactive nerve terminals in the striatum of normal, heterozygous and homozygous weaver mutant mice. J. Neurocytol. 17: 221-232.

Turner, B. H., J. S. Wilson, J. C. McKenzie, and N. Richtand (1988) MPTP produces a pattern of nigrostriatal degeneration which coincides with the mosaic organization of the caudate nucleus. Brain Res. 473: 60-64.

Vonsattel, J.-P., R. H. Myers, T. J. Stevens, R. J. Ferrante, E. D. Bird, and E. P. Richardson, Jr. (1985) Neuropathological classification of Huntington's Disease. J. Neuropathol. Exp. Neurol. 44: 559-577.

Voorn, P., C. R. Gerfen, and H. J. Groenewegen (1988a) The compartmental organization of the ventral striatum of the rat: Immunohistochemical distribution of enkephalin, substance $P$, dopamine, and calcium-binding protein. In The Dopaminergic Innervation of the Striatum in the Rat, pp. 67-78, Free University Press, Amsterdam.

Voorn, P., A. Kalsbeek, B. Jorritsma-Byham, and H. J. Groenewegen (1988b) The pre- and postnatal development of the dopaminergic cell groups in the ventral mesencephalon and the dopaminergic innervation of the striatum of the rat. Neuroscience $25: 857-888$. 